\title{
PERBEDAAN PENYULUHAN METODE DONGENG DAN PERMAINAN MONOPOLI TERHADAP PENGETAHUAN MENYIKAT GIGI PADA KELOMPOK USIA 9-10 TAHUN DI SDN 1 PALAM BANJARBARU.
}

\author{
Rini Jusy Fitriana ${ }^{1}$, Siti Salamah ${ }^{2}$ \\ Poltekkes Kemenkes Banjarmasin Jurusan Keperawatan Gigi \\ Email : d4kepgibjm@gmail.com
}

\begin{abstract}
Dental and oral health problems are quite high (> 35\%), namely South Kalimantan. One of the health professionals who can improve dental and oral health knowledge is usually done by counseling. The method used is a didactic method only active educators and the socratic method of educators and students being active and creative.

This study aims to determine the differences in counseling of fairy tales methods and monopoly games on knowledge of tooth brushing in the 9-10 year age group in SDN 1 Palam Banjarbaru. This type of research is analytical. This research design is quasiexperimental. This study was a pretest-posttest design. The number of samples is 71 respondents using total sampling or saturated sampling techniques.

The results of this study indicate that the use of fairy tale methods and monopoly game methods can both increase the knowledge of brushing teeth, but the average extension knowledge using the monopoly game method is higher than the fairy tale method, it can be seen from the magnitude of the average knowledge of brushing before counseling (10.25), after counseling (12.33) and the average difference (2.08) using the monopoly game method. Compared to the average value of tooth brushing knowledge before counseling (10.26), after counseling (11.49) and the average difference (1.23) using a fairy tale method.

The conclusion is that there are differences in the extension of fairy tale methods and the monopoly game method of knowledge of brushing teeth in the 9-10 year age group at SDN 1 Palam Banjarbaru. As for suggestions for continuous counseling using methods that are interesting and not boring so that students can help in understanding dental and oral health problems.
\end{abstract}

Keywords: counseling, fairy tales, game of monopoly, knowledge of literature: 40 (1993-2017

Correspanding Author:

Rini Jusy Fitriana,Siti Salamah

Poltekkes Banjarmasin Jur. Keperawatan Gigi

Email : d4kepgibim@gmail.com
Copyright (9) 2019 Jumal Skala Kesehatan

Politeknik Kesehatan Bargarmasin All rights reserved 


\begin{abstract}
Abstrak : Masalah kesehatan gigi dan mulut yang cukup tinggi (>35\%) yaitu Kalimantan selatan.Promkes salah satu yang dapat meningkatkan pengetahuan kesehatan gigi dan mulut biasanya dilakukan dengan penyuluhan. Metode yang digunakan adalah metode didaktik hanya pendidik yang aktif dan metode sokratik pendidik dan peserta didik bersikap aktif dan kreatif.

Penelitian ini bertujuan untuk untuk mengetahui perbedaan penyuluhan metode dongeng dan permainan monopoli terhadap pengetahuan menyikat gigi pada kelompok usia 9-10 tahun di SDN 1 Palam Banjarbaru.Jenis penelitian ini analitik.Desain peneltian ini bersifat eksperimen semu.Penelitian ini berupa rancangan pretest-posttest.Adapun jumlah sampel sebanyak 71 responden menggunakan teknik total sampling atau sampling jenuh.

Hasil penelitian ini menunjukkan bahwa penggunaan metode dongeng dan metode permainan monopoli sama-sama dapat meningkatkan pengetahuan menyikat gigi, namun rata-rata pengetahuan penyuluhan menggunakan metode permainan monopoli lebih tinggi daripada metode dongeng, terlihat dari besarnya nilai rata-rata pengetahuan menyikat gigi sebelum penyuluhan (10.25), sesudah penyuluhan (12.33) dan selisih rata-rata (2.08) menggunakan metode permainan monopoli. Dibandingkan nilai rata-rata pengetahuan menyikat gigi sebelum penyuluhan (10.26), sesudah penyuluhan (11.49) dan selisih rata-rata (1.23) menggunakan metode dongeng.

Kesimpulnya ada perbedaan penyuluhan metode dongeng dan metode permainan monopoli terhadap pengetahuan menyikat gigi pada kelompok usia 9-10 tahun di SDN 1 Palam Banjarbaru.Adapun saran agar melakukan penyuluhan yang berkesinambungan mengunakan metode bermain dengan berbagai variasi media yang menarik dan tidak membosankan agar dapat membantu murid dalam memahami masalah kesehatan gigi dan mulut.
\end{abstract}

Kata kunci : penyuluhan, dongeng, permainan monopoli, pengetahuan Kepustakaan : 40 (1993-2017 


\section{PENDAHULUAN}

Undang-Undang RI No. 36 tahun 2009 pasal 93 menjelaskan bahwa pelayanan kesehatan gigi dan mulut dilakukan untuk memelihara dan meningkatkan derajat kesehatan masyarakat dalam bentuk peningkatan kesehatan gigi, pencegahan penyakit gigi, pengobatan penyakit gigi, dan pemulihan kesehatan gigi oleh pemerintah, pemerintah daerah, dan/atau masyarakat yang dilakukan secara terpadu, terintegrasi dan berkesinambungan (Kemenkes RI, 2012).

Berdasarkan Riskesdas tahun 2007 dan 2013 permasalahan gigi dan mulut kelompok usia 5-9 tahun dan10-14 tahun mengalami peningkatan tertinggi dibanding kelompok umur yang lainnya,yakni usia 5-9 tahun $21,6 \%$ menjadi 28,9 dan usia $10-14$ tahun $20,6 \%$ menjadi $25,2 \%$. Hasil riset tentang prilaku menyikat gigi penduduk umur $\geq 10$ tahun menunjukan hanya 2,3\% penduduk Indonesia yang memiliki kebiasaan benar menyikat gigi. Berdasarkan data di atas diketahui 14 provinsi mempunyai masalah gigi dan mulut diatas angka nasional.Salah satu yang mempunyai masalah kesehatan gigi dan mulut yang cukup tinggi (>35\%) yaitu Kalimantan selatan.

Salah satu faktor penyebab timbulnya masalah kesehatan gigi dan mulut pada anak -anak adalah faktor perilaku, hal ini ditunjukan dengan anak-anak yang mengabaikan kesehatan gigi dan mulut. Hal tersebut terjadi karena kurangnya pengetahuan mengenai pentingnya menjaga kesehatan gigi dan mulut. Perilaku memegang peran penting dalam mempengaruhi kesehatan gigi dan mulut.Oleh karena itu, perilaku dapat mempengaruhi baik buruknya kebersihan gigi dan mulut, termasuk mempengaruhi angka kejadian karies (Widayati, 2014).

Menurut Herijulianti (2002) bahwa faktor prilaku ini mempunyai kontribusi yang cukup besar disamping faktor lingkungan dalam mempengaruhi derajat kesehatan masyarakat.Tingkat pelayanan pendidikan kesehatan gigi yang paling mendasari adalah promosi kesehatan, dalam tingkat ini pendidikan kesehatan gigi diperlukan untuk meningkatkan derajat kesehatan gigi misalnya dengan memilih makanan yang menyehatkan gigi, mengatur pola makanan yang mengandung gula.

Promosi kesehatan untuk meningkatkan pengetahuan biasanya dilakukan dengan penyuluhan. Metode penyuluhan yang digunakan adalah metode didaktik hanya pendidik yang aktif dan metode sokratik pendidik dan peserta didik bersikap aktif dan kreatif. Salah satu metode didaktik adalah metode dongengdan metode sokratik adalah metode permainan monopoli. Metode dongeng merupakan metode pembelajaran yang paling menarik, paling disukai, danpaling melekat dalam ingatan seorang anak karena hakekatnya sebuah cerita sulit dilupakan. Penelitianyang dilakukan Murdiono (2008) mendukung pernyataan tersebut dengan menunjukan bahwa metode dongeng merupakanmetode pembelajaran yang efektifdanpaling banyak disukai oleh anak.

Penyuluhan melalui permainan juga dapat diberikan kepada anak sebagai stimulus yang akan meningkatkan pengetahuan dan sikap terhadap permasalahan kesehatan disekitarnya, salah satunya adalah permainan monopoli. Pada penelitian Alqotahun 2010 bahwa media permainan monopoli berpengaruh terhadap hasil belajar murid-murid.metode monopoli sangat efektif sebagai media peningkatan pengetahuan, metode ini dapat digunakan untuk memberikan pengalaman menarik bagi murid dalam memahami suatu konsep, menguatkan konsep yang telah dipahami atau memecahkan masalah (Hamdani,2011).

Populasi penelitian pada rentang usia 9-10 tahun tersebut telah memiliki aspek kognitif yang teroganisasi, perkembangan motorik yang akurat, dan perkembangan emosi terkait kesadaran diri mencapai tingkah laku yang baik dan sempurna, serta kemampuan berinteraksi dan membentuk aturan dalam interaksi kelompok (Novianti, 
2009). Pengetahuan menyikat gigi lebih baik diberikan pada usia tersebut, karena pada usia tersebut menurut Sariningsih (2012) merupakan usia yang sesuai dalam melatih tanggung jawab kebersihan gigi dan mulutnya.

Berdasarkan hal tersebut penulis merasa tertarik untuk mengetahui apakah ada perbedaan pengetahuan menyikat gigi dengan penyuluhan metode dongeng dan metode permainan monopoli pada kelompok usia 9-10 tahun di SDN 1 Palam Banjarbaru.

\section{BAHAN DAN METODE}

Desain peneltian ini bersifat eksperimen semu berupa rancangan pretest-postest Tempat penelitan adalah di SDN 1 Palam Banjarbaru. Penelitian ini dilaksanakan, yaitu dari bulan Oktober 2018 sampai bulan Mei 2019.

Populasi Penelitian ini adalah sejumlah 71 orang pada semua kelompok usia 910 tahun di SDN 1 Palam Banjarbaru.

Variabel penelitian ini adalah Penyuluhan dengan metode dongeng dan permainan monopoli dan Pengetahuan Menyikat Gigi

Definisi Operasional

a. Metode Dongeng

Bercerita atau mendongeng tentang bagaimana cara menyikat gigi

b. Metode Permainan Monopoli

Monopoli merupakan suatu permainan papan dan pemain berlomba untuk mengumpulkan kekayaan melalui aturan pelaksanaan bermain

Pengukuran dilakukan dengan membagi dua kelompok penyuluhan. Dengan memberikan kode : Dongeng :1 Permainan monopoli : 2 Skala data : Nominal

c. Pengetahuan menyikat gigi : Segala sesuatu yang diketahui murid-murid tentang menyikat gigi

Pengukuran : Pengukuran dilakukan dengan kuisoner sebanyak 15 soal dengan skor jawaban, Baik 76\%-100\%

Cukup: $56 \%-75 \%$

Kurang: $<56 \%$

Alat yang digunakan adalah pengeras suara, satu set permainan monopoli, boneka dongeng dan kuesioner.

\section{HASIL DAN PEMBAHASAN}

Distribusi Frekuensi Jenis Kelamin Murid Usia 9-10 Tahun SDN 1 Palam Banjarbaru.

\begin{tabular}{c|c|c|c}
\hline No & L/ P & Jumlah & $\%$ \\
\hline 1 & Laki-laki & 31 & $43,6 \%$ \\
\hline 2 & Perempuan & 40 & $56,4 \%$ \\
\hline \multicolumn{2}{c}{ TOTAL } & 71 & $100 \%$ \\
\hline
\end{tabular}

bahwa jumlah murid SDN 1 Palam Banjarbaru sebanyak 71 murid dengan jenis kelamin laki-laki sebanyak 31 murid $(43,6 \%)$ jenis kelamin perempuan 40 murid $(56,4 \%)$. 
Distribusi Frekuensi Umur Murid 9-10 Tahun SDN 1 Palam Banjarbaru.

\begin{tabular}{c|c|c|c}
\hline No & Umur & Jumlah & $\%$ \\
\hline 1 & 9 Tahun & 30 & $42,2 \%$ \\
\hline 2 & 10 Tahun & 41 & $57,8 \%$ \\
\hline \multicolumn{2}{c}{ TOTAL } & 71 & $100 \%$ \\
\hline
\end{tabular}

jumlah siswa SDN 1 Palam Banjarbaru sebanyak 71 murid dengan umur 9 tahun sebanyak 30 murid (42,2\%), umur 10 tahun sebanyak 41 murid (57,8 \%).

Hasil Analisis Pengetahuan Menyikat Gigi Sebelum dan Sesudah Penyuluhan

Dengan Metode Dongeng

\begin{tabular}{c|c|c|c|c|c}
\hline $\begin{array}{c}\text { Media } \\
\text { Dongeng }\end{array}$ & Mean & Mode & Median & $\begin{array}{c}\text { Std. } \\
\text { Deviasi }\end{array}$ & Min-Max \\
\hline Sebelum & 10.26 & 11.00 & 11.00 & 1.540 & $6-13$ \\
\hline Sesudah & 11.49 & 13.00 & 11.00 & 1.821 & $7-14$ \\
\hline
\end{tabular}

Data diatas menunjukkan sebelum dilakukan penyuluhan metode dongeng didapatkan nilai rata-rata(mean) adalah 10.26,std-deviationadalah 1.540 dan sesudah dilakukan penyuluhan metode dogeng didapatkan nilai rata-rata(mean) adalah 11.49 dengan Std- deviasi adalah 1.821

Hasil Analisis Pengetahuan Menyikat Gigi Sebelum dan Sesudah Penyuluhan Dengan Metode Permainan Monopoli

\begin{tabular}{l|c|c|c|c|c}
\hline Monopoli & Mean & Mode & Median & $\begin{array}{c}\text { Std. } \\
\text { Deviatio } \\
n\end{array}$ & $\begin{array}{c}\text { Min- } \\
\text { Max }\end{array}$ \\
\hline Sebelum & 10.25 & 11.00 & 11.00 & 1.461 & $7-12$ \\
\hline Sesudah & 12.33 & 13.00 & 13.00 & 1.373 & $8-15$ \\
\hline
\end{tabular}

- Hasil Uji Independent Sample T-test Metode Dongeng dan Metode Permainan Monopoli

\begin{tabular}{|c|c|c|c|c|c|c|c|}
\hline & \multicolumn{2}{|c|}{$\begin{array}{l}\text { Levene's } \\
\text { Test for } \\
\text { Equality of } \\
\text { Variances }\end{array}$} & \multicolumn{4}{|c|}{ t-test for Equality of Means } \\
\hline & & $F$ & Sig. & $t$ & Df & $\begin{array}{l}\text { Sig. }(2- \\
\text { tailed) }\end{array}$ & $\begin{array}{c}\text { Mean } \\
\text { Difference }\end{array}$ \\
\hline \multirow[t]{2}{*}{$\begin{array}{l}\text { Peningkata } \\
\text { Pengetahu: }\end{array}$} & $\begin{array}{l}\text { Equal } \\
\text { variances } \\
\text { Assumed }\end{array}$ & $\begin{array}{r}3.69 \\
3\end{array}$ & .059 & 2.920 & 69 & .005 & 0.85 \\
\hline & $\begin{array}{l}\text { Equal } \\
\text { variances } \\
\text { not } \\
\text { assumed }\end{array}$ & & & 2.933 & $\begin{array}{r}64.3 \\
12\end{array}$ & .005 & 0.85 \\
\hline
\end{tabular}

hasil uji independent sample $T$-test, angka pada kolom sig bernilai 0.059 dengan nilai alpha 0.05 berarti $\rho>\alpha$, sehingga yang dibaca pada baris equal variances assumed artinya kedua data kelompok ini dianggap homogen. Pada kolom sig (2- 
tailed) 0.005 dengan nilai alpha 0.05 sehingga dapat disimpulkan bahwa $\rho<\alpha$ artinya $H_{0}$ ditolak dan $\mathrm{Ha}$ diterima, berarti ada perbedaan penyuluhan metode dongeng dan metode permainan monopoli terhadap pengetahuan menyikat gigi pada kelompok usia 9-10 tahun di SDN 1 Palam Banjarbaru.

\section{PEMBAHASAN}

Berdasarkan tabel 5.4 terdapat peningkatan sebelum dan sesudah dilakukan penyuluhan menggunakan metode dongeng dikarenakan penyuluhan menggunakan metode dongeng merupakan metode pembelajaran yang paling menarik, paling disukai, dan paling melekat dalam ingatan seorang anak karena hakekatnya sebuah cerita sulit dilupakan. Hasil penelitian ini sesuai dengan penelitian Murdiono (2008) tersebut dengan menunjukan bahwa metode dongeng merupakan metode pembelajaran yang efektif dan paling banyak disukai oleh anak.

Berdasarkan tabel tersebut terdapat peningkatan sebelum dan sesudah dilakukan penyuluhan menggunakan metode permainan monopoli dikarenakan metode permainan monopoli merupakan salah satu stimulus yang akan meningkatkan pengetahuan dan sikap terhadap permasalahan kesehatan disekitarnya. Permainan monopoli juga sebagai permainan edukatif sehingga anak-anak dapat bermain sambil belajar.Permainan ini sangat menyenangkan dan tidak membosankan karena anakanak dapat bermain sambil memecahkan masalah, dan menambah pengetahuan. Hasil penelitian ini sesuai dengan penelitian yang dilakukan Alqo (2010) bahwa permainan monopoli berpengaruh terhadap hasil belajar murid-murid. metode monopoli sangat efektif sebagai media peningkatan pengetahuan, metode ini dapat digunakan untuk memberikan pengalaman menarik bagi murid dalam memahami suatu konsep, menguatkan konsep yang telah dipahami atau memecahkan masalah (Hamdani, 2011).

Berdasarkan rekaputasi data pengetahuan metode dongeng lebih banyak murid yang tidak mengalami peningkatan pengetahuan dibandingkan dengan metode permainan monopoli ini dikarenakan murid-murid lebih antusias untuk bermain monopoli dari pada hanya duduk mendengarkan cerita dongeng. Perminan monopoli sangatlah menarik karena murid-murid sudah mengetahui dan paham akan permainan ini dan mereka dapat langsung bermain sambil belajar tentang pengetahuan menyikat gigi. Sedangkan dengan metode dongeng murid-murid hanya diam duduk mendengarkan cerita dongeng dan murid-murid merasa bosan dan bahkan ada yang tidak mendengarkan cerita dongeng tersebut

Berdasarkan hasil penelitian menunjukkan bahwa penggunaan metode dongeng dan metode permainan monopoli sama-sama dapat meningkatkan pengetahuanmenyikat gigi, namun rata-rata pengetahuanpenyuluhan menggunakan metode permainan monopoli lebih tinggi daripada metode dongeng, terlihat dari besarnya selisih nilai rata-rata pengetahuan menyikat gigi sebelum dan sesudah penyuluhan menggunakan metode permainan monopoli $(2,08)$ dibandingkan menggunakan metode dongeng (1.23), hal ini karena metode permainan monopoli lebih menarik perhatian peserta didik dalam situasi pembelajaran awal maupun akhir dalam rangkaian pelajaran.

Metode permainan monopoli juga lebih banyak menggunakan indra pendengar dan indra penglihatan, serta melibatkan langsung keikutsertaan muri-murid sehingga informasi dapat diterima dengan baik, lebih menarik karena murid bermain bersama teman-temannya sekaligus sambil belajar. Sedangkan metode dongeng dapat menimbulkan kebosanan pada murid apabila digunakan terlalu lama, sehingga murid tidak terlalu memperhatikan apa yang disampaikan oleh penyuluh. 
Hasil ini diperkuat dengan hasil analisis SPSS melalui uji Independent Test diperoleh nilai $\mathrm{p}$ 0.005, maka $\mathrm{p}<$ a sehinggaHo ditolak dan Ha diterima, berarti ada perbedaan pengetahuan menyikat gigi menggunakan metode dongeng dan metode permainan monopoli terhadap pengetahuan menyikat gigi pada kelompok usia 9-10 tahun di SDN 1 Palam Banjarbaru.

Pada usia sekolah dasar biasanya anak akan lebih menyukai bermain sambil belajar menggunakan permainan yang menarik untuk memudahkan penangkapan isi materi yang diberikan, pada usia 9-10 tahun adalah usia dimana anak sudah bisa menyimak dan meyimpulkan materi yang disampaikan penyuluh. Anak-anak akanmulai fokus untuk menerapkan pembelajaran yang didapatkannya dari penyuluh. Adanya kondisi ini sesuai dengan teori Edgar Dale yang mengatakan bahwa semakin konkrit media maka tingkat penerimaan sasaran menjadi lebih baik, sebaliknya semakin abstrak sebuah media maka tingkat penerimaan menjadi kurang.Dalam hal ini bermain lebih memberikan pengalaman konkrit kepada sasaran, karena dengan bermain sasaran dapat langsung berperan aktif sehingga dapat mengamati, mengenal dan mengingat dengan lebih jelas (Prakoso dkk, 2016).

Rasa menyenangkan dan lebih menarik jika dilakukan pada anak-anak, mendorong kesatuan dan mendapatkan hasil yang nyata (Djay, 2009).Pada penelitian ini dapat dilihat bahwa penyuluhan kesehatan gigi dan mulut dengan metode bermain memberikan pengaruh pada pengetahuan kesehatan gigi dan mulut karena metode bermain ini dapat merangsang daya ingat anak-anak dalam penyuluhan kesehatan gigi dan mulut.

Pemberian informasi tentang kesehatan gigi dan mulut melalui media yang mudah dipahami akan meningkatkan pengetahuan anak tentang hal tersebut. Selanjutnya dengan pengetahuan tersebut akan menimbulkan kesadaran mereka, dan akhirnya akan menyebabkan anak tersebut bersikap sesuai dengan pengetahuan yang dimilikinya (Notoatmodjo, 2007).

\section{KESIMPULAN}

Hasil penelitian perbedaan penyuluhan metode dongeng dan metode permainan monopoli terhadap pengetahuan menyikat gigi pada kelompok usia 9-10 tahun di SDN

1 Palam Banjarbaru

1. Rata-rata pengetahuan menyikat gigi sebelum penyuluhan metode dongeng pada kelompok usia 9-10 di SDN 1 Palam Banjarbaru sebesar 10.26.

2. Rata-rata pengetahuan menyikat gigi sesudah penyuluhan metode dongeng pada kelompok usia 9-10 di SDN 1 Palam Banjarbaru sebesar 11.49.

3. Rata-rata pengetahuan menyikat gigi sebelum penyuluhan metode permainan monopoli pada kelompok usia 9-10 tahun di SDN 1 Palam Banjarbaru sebesar 10.25 .

4. Rata-rata pengetahuan menyikat gigi sesudah penyuluhan metode permainan monopoli pada kelompok usia 9-10 tahun di SDN 1 Palam Banjarbaru sebesar 12.33

5. Ada perbedaan penyuluhan metode dongeng dan metode permainan monopoli terhadap pengetahuan menyikat gigi pada kelompok usia 9-10 tahun di SDN 1 Palam Banjarbaru. 


\section{DAFTAR PUSTAKA}

Adriana D, 2011. Tumbuh Kembang Dan Therapy Bermain Pada Anak. Jakarta: Salemba Medika.

Afifah AY, 2017. Pengaruh Storytelling Terhadap Perilaku Menggosok Gigi pada murid kelas IV dan V di SD Banyuripan Bangunjiwo Kasih Bantul, Fakultas Kedokteran Gigi, Universitas Aisyiyah Yogyakarta.Skripsi.

Ali Z, 2010, Pengantar Keperawatan Keluarga. Jakarta :EGC.

Ardiwirastuti I,2016. Perbedaan Metode Penyuluhan Permainan Outbond, Monopoli, Dan Ceramah Dalam Meningkatkan Kesehatan Gigi Dan Mulut pada Murid Kelas IV, V,VI SDN Sumbersari 03 Jember, Fakultas Kedokteran Gigi, Universitas Jember. Skripsi.

Danim S, 2006. Motivasi Kepemimpinan dan efektifitas kelompok.Jakarta : RenekaCipta

Depkes RI, 2000. Pedoman Upaya Pelayanan Kesehatan Gigi Dan Mulut Dipuskesmas, Jakarta.

---, 2010.Profil Kesehatan Indonesia.Jakarta : Depkes RI. --, 2013. Riset Kesehatan Dasar (Riskesdas). Jakarta: Badan Penelitian Dan

Pengembangan Kesehatan, Departemen Kesehatan Republik Indonesia.

Gupte S, 2004. Panduan Perawatan Anak. Jakarta :Pustaka Populer Obor.

Hamdani, 2011.Strategi Belajar Mengajar. Bandung : Pustaka Setia

Hermawan R, 2010. Menyehatkan Daerah Mulut, Jogjakarta : Bukubiru.

Herijulianti, Eliza dkk, 2002. Pendidikan Kesehatan Gigi. Jakarta : EGC

Hockenberry M.J, Wilson D, 2007. Nursing Care Of Infants And Children. (8th

Ed.). St.Louis: Mosby Elsevier.

Houwink B, dkk, 1993. Ilmu Kedokteran Gigi Pencegahan, Gadjah Mada University Press, Yogyakarta.

Kementrian Kesehatan RI, 2012. Buku Panduan Pelatihan Kader Kesehatan Gigi dan Mulut di Masyarakat, Kementrian Kesehatan Ri. Jakarta.

Machfoedz AY, 2005. Menjaga Kesehatan Gigi dan Mulut Anak-Anak dan Ibu Hamil.Yogyakarta : Tramaya.

Machfoez.I, Suryani E, 2006. Pendidikan Kesehatan Bagian dari Promosi Kesehatan, Yogyakarta : Fitramaya.

Margareta S, 2012. 101 Tips Dan Terapi Alami Agar Gigi Putih Dan Sehat. Edisi 1. Pustaka Cerdas : Yogyakarta.

Maulana HDJ, 2009. Promosi Kesehatan.Jakarta: EGC.

Tedjasaputra MS, 2010. Bermain Mainan Dan Permainan. Jakarta: Grasindo.

Notoatmodjo S, 2003.Pendidikan dan Perilaku Kesehatan. Jakarta: Rineka Cipta.

----------, 2005. Promosi Kesehaan Teori dan Aplikasi, Jakarta : Rineka Cipta. -, 2007. Promosi Kesehatan dan IImu Prilaku, Jakarta : Rineka Cipta.

Putodologi Penelitian Kesehatan, Jakarta : Rineka Cipta.

Putri MH, Herijulianti E, Nurjannah N, 2010. Ilmu Pencegahan Penyakit Jaringan Keras dan Jaringan Pendukung Gigi, Jakarta :Buku Kedokteran EGC.

Potter PA, Perry AG, 2005. Buku Ajaran Fundamental Keperawatan Konsep, Proses, dan Praktik. Edisi 4 Volume 1, Jakarta :EGC.

Pratiwi D, 2009. Gigi Sehat dan Cantik, Perawatan Praktis Sehari-Hari, Jakarta : Kompas Media Nusantara.

Rahmawati, 2009.Permainan Tradisional Untuk Anak. Bandung.Sandiarta Sukses Bandung: Refika Aditama.

Ramadhan AG, 2010. Serba-Serbi Kesehatan Gigi dan Mulut.Jakarta : Bukume. 
Sariningsih E, 2012. Merawat Gigi Anak Sejak Usia Dini, Jakarta :. Elekemdia, Komputindo.

Soebroto I, 2009.Apa yang Tidak Dikatakan Dokter Tentang Kesehatan Gigi Anda, Yogyakarta : Bookmarks.

Sriyono NW, 2009. Pencegahan Penyakit Gigi Dan Mulut Guna Meningkatkan Kualitas Hidup (Pidato Pengukuhan), Fakultas Kedokteran Gigi Universitas Gadjah Mada, Yogyakarta.

Sukardi DK, 1995, Proses Bimbingan dan Penyuluhan, Bandung : Rineka Cipta.

Syahsiyah, 2008.Pengaruh Permainan Monopoli Sebagai Media Pembelajaran Terhadap Minat Pelajar pada Siswa Sekolah Dasar Kelas V SDIT Al-Hikmah, Fakultas IImu Tarbiyah dan Keguruan, Universitas Islam Negeri Syarif Hidayatulloh Jakarta.Skripsi.

Wawan A, dan Dewi M, 2010. Teori Pengukuran Pengetahuan, Sikap, Perilaku Manusia, Yogykarta.

Widayati N, 2014. Faktor Yang Berhubungan dengan Karies Gigi pada Anak Usia 4-6 Tahun. Surabaya :Jurnal Berkala Epidemiologi.2(2): 196-205.

Zaskia S, 2016. Anak Hebat Berkat Hipodongeng. Yogyakarta : Laksana 